\title{
PELATIHAN PEMBUATAN DAN PENGGUNAAN GOOGLE SITES SEBAGAI MEDIA PEMBELAJARAN KEPADA GURU MADRASAH ALIYAH SE-KABUPATEN BOALEMO
}

\section{Training To Create And Use Google Sites As A Learning Media For Madrasah Aliyah Teachers In Boalemo District}

\author{
Herinda Mardin ${ }^{1)}$, La Nane ${ }^{2)}$ \\ ${ }^{1}$ Jurusan Biologi Universitas Negeri Gorontalo \\ ${ }^{2}$ Jurusan Manajemen Sumber Daya Perairan Universitas Negeri Gorontalo \\ Email: herindamardin@ung.ac.id ${ }^{1)}$
}

\begin{abstract}
ABSTRAK
Pembelajaran di era pandemi covid-19 membuat guru memaksimalkan penggunaan media pembelajaran berbasis ICT. Untuk itu dibutuhkan berbagai upaya dalam pembelajaran termasuk penggunaan media pembelajaran berbasis ICT agar memudahkan guru dalam proses pembelajaran. Pentingnya peningkatan kompetensi dan keterampilan guru dalam memanfaatkan dan memaksimalkan media pembelajaran berbasis ICT sehingga perlu adanya pelatihan dalam membuat dan menggunakan media pembelajaran berbasis ICT kepada guru. Pelatihan pembuatan dan penggunaan google sites sebagai media pembelajaran dilaksanakan di Madrasah Aliyah Negeri (MAN) 1 Boalemo Kabupaten Boalemo Provinsi Gorontalo pada hari kamis, 09 Juli 2020. Pelatihan ini bertujuan untuk meningkatkan kompetensi guru tingkat Madrasah Aliyah se-kabupaten Boalemo melalui penggunaan Google Sites sebagai media pembelajaran. Pelaksanaan pelatihan ini terdiri atas 2 tahapan yaitu pertama penyampaian materi mengenai pembuatan dan penggunaan google sites sebagai media pembelajaran dan kedua praktek langsung membuat dan menggunakan google sites sebagai media pembelajaran. Metode dalam pelatihan ini adalah ceramah, tanya jawab dan eksperimen. Pelatihan ini diikuti dengan antusiasme dari peserta yang diikuti oleh 35 orang guru tingkat Madrasah Aliyah se-kabupaten Boalemo. Pelatihan ini menambah pengetahuan dan kompetensi serta skill peserta dalam membuat dan menggunakan google sites sebagai media pembelajaran.
\end{abstract}

Kata kunci: Pelatihan; google sites; media pembelajaran

\begin{abstract}
Learning in the era of the Covid-19 pandemic has forced teachers to maximize the use of ICT-based learning media. For this reason, various efforts are needed in learning including the use of ICT-based learning media to make it easier for teachers in the learning process. The importance of increasing the competence and skills of teachers in utilizing and maximizing ICT-based learning media is pivotal, therefore, there is a need for training in creating and using ICT-based learning media for teachers. Training to use and operate the google sites as a learning medium was held at MAN 1 Boalemo, Boalemo Regency, Gorontalo Province on Thursday, July 9th, 2020. This training aims to improve the competence of all teachers from the Madrasah Aliyah in Boalemo district through the use of Google Sites as a learning medium. The implementation of this training consists of 2 stages, firstly, the delivery of material regarding how to create an account and use of google sites as
\end{abstract}


a learning medium and secondly, direct practice of creating and using google sites as a learning medium. The methods in this training are lectures, questions and answers and also experiments. This training was followed by participant with huge enthusiasm, which was attended by 35 teachers at Madrasah Aliyah level in Boalemo district. This training adds to the knowledge and competence of participants in creating and using google sites as a learning medium.

Keywords: Training; google sites; learning media

\section{PENDAHULUAN}

Perkembangan teknologi informasi dan komunikasi begitu pesatnya tak terkecuali dalam dunia pendidikan. Di era pandemi covid-19 membuat guru memaksimalkan penggunaan media pembelajaran berbasis ICT.

Berbagai upaya dilakukan dalam meningkatkan pengetahuan, kompetensi dan skill guru dalam penggunaan media pembelajaran salah satunya dengan pelatihan media pembelajaran berbasis WEB (Taufik, Muhammad. 2018).

Proses pembelajaran di era pandemi covid-19 yang dilakukan secara daring tentu saja memiliki kendala seperti akses jaringan internet di beberapa daerah yang sulit mengakses jaringan internet. Tetapi di daerah yang mampu menerapkan pembelajaran daring tentu saja akan memaksimalkan penggunaan berbagai media pembelajaran berbasis ICT, salah satunya dengan menggunakan google sites sebagai media pembelajaran. Hal ini sejalan dengan hasil penelitian Januarisman Erwin dan Ghufron Anik (2016) dan Vidia Sari Heni dan Suswanto Hary (2017) bahwa penggunaan media pembelajaran berbasis WEB efektif dan efisien dilakukan karena meningkatkan hasil belajar peserta didik.

Melalui media pembelajaran berbasis google sites ini materi pembelajaran dapat dengan mudah diakses oleh peserta didik. Beberapa kesulitan belajar dapat dialami oleh peserta didik dalam belajar. Misalnya salah satu kesulitan belajar biologi yang dialami oleh peserta didik adalah karakteristik topik dan gaya mengajar guru yang kurang kreatif (Mardin, Herinda. 2017). Untuk itu dibutuhkan media pembelajaran yang baik dalam proses pembelajaran.

Google sites sebagai media pembelajaran dapat dimanfaatkan oleh guru dalam mengupload video pembelajaran yang materi dan karakteristik topic materi tersebut sangat abstrak sehingga materinya dengan mudah dapat dipahami oleh peserta didik. Melalui google sites juga guru dapat mengintegrasikan beberapa link materi dan link soal kepada peserta didik sehingga google sites juga dapat digunakan sebagai Learning Managemen System (LMS).

Contoh lain manfaat penggunaan google sites sebagai media pembelajaran misalnya guru biologi akan mengajarkan materi hewan invertebrata untuk materi Echinodermata khususnya bulu babi bahwa berdasarkan hasil penelitian (Nane, et al. 2020) yang dilakukan di pantai Blue Marlin Gorontalo, rata-rata diameter bulu babi pada bulan November dan Desember 2019 serta Januari 2020 masing-masing $60 \mathrm{~mm}$, $63 \mathrm{~mm}$ dan $66 \mathrm{~mm}$. Kepadatan bulu babi di pantai Blue Marlin Gorontalo sangat rendah. Guru dapat memberikan dan menjelaskan materi Echinodermata dengan mengambil langsung materi dari jurnal hasil penelitian terkait dengan materi tersebut lalu mengupload link jurnal hasil penelitian itu pada media pembelajara sehingga peserta didik kaya akan sumber belajar.

Berbagai manfaat dari penggunaan google sites sebagai media pembelajaran telah banyak dirasakan bagi guru dan peserta didik apalagi disaat era pandemi 
covid-19 sehingga dibutuhkan kegiatan yang dapat meningkatkan pengetahuan, kompetensi dan skill bagi guru agar memaksimalkan penggunaan media pembelajaran berbasis ICT yaitu dalam membuat dan menggunakan google sites sebagai media pembelajaran

\section{Permasalahan Mitra}

Bagi guru, kebutuhan akan media pembelajaran berbasis ICT menjadi tak terelakkan di era pandemic covid-19 dalam proses pembelajaran. Guru harus memiliki kompetensi dan skill dalam membuat dan menggunakan media berbasis ICT. Pentingnya peningkatan kompetensi guru dalam memaksimalkan penggunaan media pembelajaran berbasis ICT di era pandemic covid-19 sehingga dibutuhkan upaya dalam meningkatkan kompetensi tersebut.

\section{SOLUSI DAN TARGET LUARAN}

\section{Solusi Permasalahan}

Adapun usaha yang dapat dilakukan sebagai solusi dari permasalahan tersebut yaitu dengan mengadakan pelatihan pembuatan dan penggunaan google sites sebagai media pembelajaran dalam upaya meningkatkan pengetahuan, kompetensi dan skill guru.

\section{Luaran dan Target Capaian}

Adapun luaran dan target capaian dari kegiatan pelatihan ini adalah sebagai berikut.

1. Guru memiliki pengetahuan mengenai media pembelajaran berbasis ICT

2. Guru memiliki kompetensi dan skill dalam membuat dan menggunakan google sites sebagai media pembelajaran.

3. Memudahkan guru dalam melakukan proses pembelajaran menggunakan media pembelajaran berbasis ICT yaitu menggunakan google sites sebagai media pembelajaran kepada peserta didik.

\section{METODE PELAKSANAAN KEGIATAN}

Pada kegiatan pelaksanaan pelatihan ini akan didampingi oleh tim pelatihan. Kegiatan pelatihan ini dilakukan dalam 2 tahapan yaitu pertama pemberian materi mengenai google sites sebagai media pembelajaran dan kedua adalah praktek langsung membuat dan menggunakan google sites sebagai media pembelajaran.

Metode kegiatan pelatihan ini dengan menggunakan metode ceramah, tanya jawab dan eksperimen. Metode pelatihan dapat diuraikan sebagai berikut:

- Kegiatan pelatihan diawali koordinasi dengan kepala sekolah Madrasah Aliyah Negeri (MAN) 1 Boalemo tentang waktu untuk melaksanakan kegiatan pelatihan.

- Pihak sekolah menyediakan fasilitas berupa akses jaringan internet untuk digunakan saat kegiatan pelatihan

- Kegiatan pelatihan dilaksanakan pada hari kamis 09 Juli 2020 bertempat di Aula Sekolah Madrasah Aliyah Negeri (MAN) 1 Boalemo.

- Pelatihan tahap pertama diawali dengan pemberian materi menggunakan metode ceramah mengenai media pembelajaran berbasis ICT dan cara membuat dan menggunakan google sites sebagai media pembelajaran. Pada pelatihan tahap pertama juga terjadi tanya jawab antara peserta dan narasumber mengenai materi yang disampaikan oleh narasumber.

- Pelatihan tahap kedua yakni eksperimen dimana peserta membuat langsung media pembelajaran berdasarkan mata pelajaran masing-masing peserta menggunakan google sites.

Setelah kegiatan pelatihan ini nantinya tim pelatihan akan terus menjalin komunikasi dengan pihak mitra tentang penggunaan google sites sebagai media pembelajaran. Diharapkan melalui kegiatan 
pelatihan ini dapat meningkatkan pengetahuan, kompetensi dan skill guruguru dalam membuat dan menggunakan google sites sebagai media pembelajaran sehingga hasil belajar peserta didik dapat meningkat.

\section{HASIL DAN PEMBAHASAN}

Hasil dari pelaksanaan kegiatan pelatihan pembuatan dan penggunaan google sites sebagai media pembelajaran kepada guru madrasah aliyah se-kabupaten Boalemo adalah sebagai berikut:

1. Jumlah peserta sebanyak 35 orang yang terdiri dari guru-guru madrasah aliyah se-kabupaten Boalemo.

2. Peserta pelatihan pembuatan dan penggunaan google sites sebagai media pembelajaran yang terdiri guru-guru madrasah aliyah se-kabupaten Boalemo memberikan respon yang sangat baik dan mereka sangat tertarik dengan materi yang disampaikan. Karena cara membuat dan menggunakan google sites mudah dan sangat membantu dalam memberikan materi pelajaran kepada peserta didik.

3. Peserta pelatihan pembuatan dan penggunaan google sites sebagai media pembelajaran sangat aktif melakukan eksperimen dengan membuat media pembelajaran menggunakan google sites.

4. Kegiatan pelatihan ini memberikan manfaat dan inspirasi bagi guru khususnya guru-guru madrasah aliyah se-kabupaten Boalemo dalam mengembangkan media pembelajaran berbasis ICT yang inovatif.

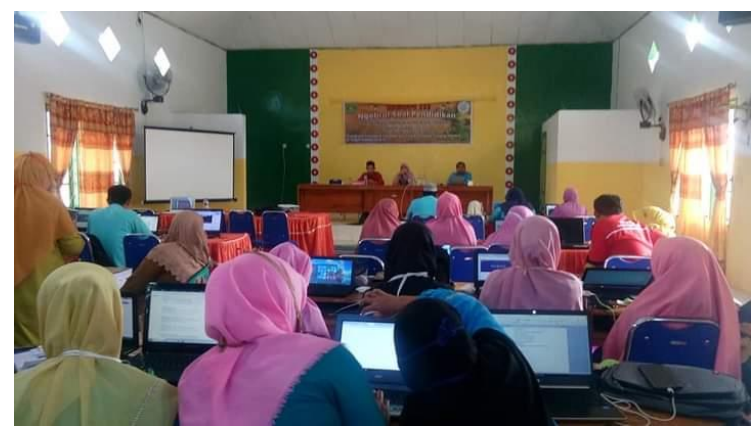

Gambar 1. Pemberian materi mengenai cara membuat dan menggunakan google sites sebagai media pembelajaran

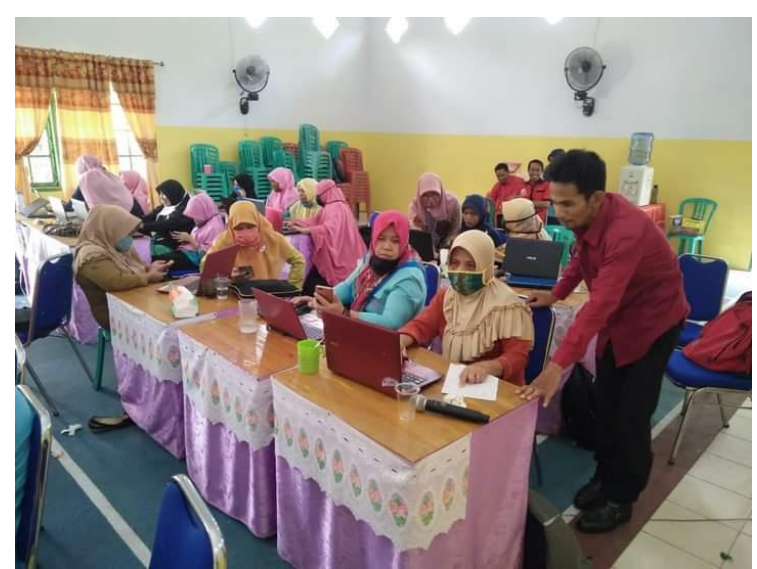

Gambar 2. Proses pelatihan membuat dan menggunakan media pembelajaran menggunakan google sites

Pada gambar 1 terlihat peserta dengan antusias mendengarkan materi yang dismapaikan oleh narasumber mengenai cara membuat dan menggunkan google sites sebagai media pembelajaran.

Pada gambar 2 merupakan proses pendampingan kepada guru-guru dalam membuat dan menggunakan google sites sebagai media pembelajaran. Terdapat kendala yang dihadapi dalam proses pelatihan pembuatan dan penggunaaan google sites sebagai media pembelajaran adalah jaringan yang yang awalnya kurang baik tetapi segera difasilitasi oleh pihak sekolah sehingga kegiatan pelatihan berjalan dengan sangat baik dan lancar hingga akhir. 
Keterlaksanaan kegiatan ini berjalan dengan baik dan lancar didukung oleh beberapa faktor sebagai berikut.

1. Keinginan dan minat yang tinggi dari peserta dalam mengikuti kegiatan pelatihan ini. Peserta sangat tertarik mengikuti kegiatan pelatihan ini karena penggunaan google sites sebagai media pembelajaran dianggap masih baru

2. Pihak sekolah Madrasah Aliyah Negeri (MAN) 1 Boalemo sangat mendukung kegiatan pelatihan ini dengan menyediakan fasilitas tempat, konsumsi bagi peserta dan jaringan internet yang kuat sehingga dalam membuat media pembelajaran bisa dilakukan maksimal oleh peserta.

3. Respon yang sangat baik dari peserta pelatihan dalam mengikuti kegiatan pelatihan ini. Peserta begitu antusias mengikuti kegiatan pelatihan pembuatan dan penggunaan google sites sebagai media pembelajaran ini.

\section{UCAPAN TERIMAKASIH}

Terimakasih kepada kepala sekolah Madrasah Aliyah Negeri (MAN) 1 Boalemo bapak Erman Hubu, S.Pd., M.Pd dan bapak/ibu guru Madrasah Aliyah Negeri (MAN) 1 Boalemo yang telah memfasilitasi kegiatan pelatihan ini sehingga kegiatan pelatihan ini berjalan dengan sangat baik dan lancar.

\section{KESIMPULAN DAN SARAN}

Pelatihan diikuti oleh 35 orang peserta dengan antusiasme yang tinggi dan aktif dalam membuat media pembelajaran menggunakan google sites. Pelatihan pembuatan dan penggunaan google sites sebagai media pembelajaran meningkatkan pengetahuan, kompetensi dan keterampilan guru madrasah aliyah se-kabupaten Boalemo dalam membuat dan menggunakan google sites sebagai media pembelajaran.

\section{DAFTAR PUSTAKA}

Januarisman, Erwin dan Ghufron, Anik. 2016. Pengembangan Media Pembelajaran Berbasis Web Mata Pelajaran Ilmu Pengetahuan Alam Untuk Siswa Kelas VII. Jurnal Inovasi Teknologi Pendidikan Volume 3, No 2, Oktober 2016 (166-182)

Mardin, Herinda. (2017). Analisis Kesulitan Belajar Biologi Peserta Didik Kelas XII IPA SMA Negeri di Kota Palopo. S2 thesis, Universitas Negeri Makassar. E-prints Repository Software Universitas Negeri Makassar. http://eprints.unm.ac.id/5840/

Nane, et al. 2020. Density of the blue-black urchin Echinotrix diadema (Linnaeus, 1758) in Tomini Bay, Indonesia. Tomini Journal of Aquatic Science. May 2020. Vol 1(1): 16-21,

Taufik, Muhammad. Et al. (2018). Pelatihan Media Pembelajaran Berbasis WEB Kepada Guru IPA SMP Kota Mataram. Jurnal Pendidikan dan Pengabdian Masyarakat Vol. 1 No. 1. Februari 2018 (e-ISSN. 2614-7939, pISSN. 2614-7947). Hal 77-81.

Vidia Sari Heni dan Suswanto Hary. 2017. Pengembangan Media Pembelajaran Berbasis Web Untuk Mengukur Hasil Belajar Siswa Pada Mata Pelajaran Komputer Jaringan Dasar Program Keahlian Teknik Komputer Dan Jaringan. Jurnal Pendidikan: Teori, Penelitian, dan Pengembangan Volume: 2 Nomor: 7 Bulan Juli Tahun 2017 Halaman: 1008-1016. 